\title{
REESTRUTURAÇÕES CURRICULARES NAS LICENCIATURAS: UM ENSAIO TEÓRICO SOBRE AS DUAS FACES - A LEGISLATIVA E A REAL
}

Tais Andrade dos Santos ${ }^{1}$, Moacir Pereira de Souza Filho ${ }^{2}$

${ }^{1}$ Doutoranda em Educação para Ciência do Programa Pós- Graduação em Educação para a Ciência pela Universidade Estadual Paulista - UNESP, Bauru, SP. E-mail: taisandradedossantos@gmail.com

${ }^{2}$ Doutor em Educação para a Ciência pela Universidade Estadual Paulista - UNESP, Bauru, SP. Docente Assistente Doutor do Departamento Física e docente credenciado no Programa Nacional de Mestrado Profissional em Ensino de Física - UNESP, Presidente Prudente/SP, no Programa de Pós-Graduação em Educação para a Ciência - UNESP, Bauru, SP e no Programa de Pós-Graduação em Ensino de Ciências - Doutorado no Instituto de Física - UFMS, Campo Grande, MS.

\section{RESUMO}

A formação inicial de professores no contexto brasileiro depende de uma pluralidade de diretrizes que direcionam a formação inicial e profissionalização docente. Este ensaio teórico foi elaborado com o objetivo de discutir a problemática da adequação curricular na formação inicial de professores, a partir de diretrizes estruturadoras dos cursos de licenciaturas, ponderando a importância das ideologias préexistentes do Professor Formador. Neste trabalho temos como principais referenciais Apple (2006) e Sacristán (2008) para a discussão de currículo e o Parecer CNE/CP no 111/2012 como exemplificação nesta discussão. Como resultado dessa reflexão, consideramos que se torna imprescindível a formação continuada de professores formadores, para que haja um espaço de reflexão sobre o que significa formar um professor e sobre a cultura de sua vivencia dentro da universidade, possibilitando a ruptura ideológica do formador e também construindo e desequilibrando hegemonias no âmbito dos colegiados, ao construírem os currículos das licenciaturas.

Palavras-chave: Formação Inicial de Professores. Estrutura Curricular. Parecer no111/2012.

\section{CURRICULAR RESTRUCTURING IN THE TEACHING TRAINING COURSE: A THEORETICAL TEST ON THE BOTH FACES - LEGISLATIVE AND REAL}

\begin{abstract}
The initial formation of teachers in the Brazilian context depends on a plurality of guidelines that guide the initial formation and teacher professionalization. This theoretical essay was elaborated with the objective of discussing the problem of curricular adequacy in the initial formation of teachers, based on the structuring guidelines of the degree courses, pondering the importance of the pre-existing ideologies of the Trainer Teacher. In this work we have as main references Apple (2006) and Sacristán (2008) for the discussion of curriculum and Opinion CNE / CP no 111/2012 as an example in this discussion. As a result of this reflection, we consider that it is essential to continue the formation of teacher trainers, so that there is a space for reflection on what it means to train a teacher and about the culture in which their experience within the university, enabling the ideological rupture of the teacher and also building and unbalancing hegemonies within the colleges by building curricula for undergraduate degrees.
\end{abstract}

Keywords: Initial Teacher Training; Curricular Structure, Law no 111 / 2012.

\section{INTRODUÇÃO}

Discutir a profissão docente e sua formação em um único ensaio teórico é praticamente impossível devido ao fato da existência de uma pluralidade de questões a serem levantadas e de focos de cada curso. Neste caso, nossa discussão centra-se nas políticas brasileiras (diretrizes estruturadoras de currículo) que estruturam a Formação Inicial de Professores da Educação Básica, em nível superior em curso de licenciatura de graduação plena e, que 
caracterizam-se por suas duas faces: a legislativa e o real.

No Brasil, segundo a atual Lei de Diretrizes e Bases da Educação Nacional (LDB 1996), no que diz respeito a organização da educação nacional, as diretrizes que estruturam os cursos de licenciatura seguem uma hierarquia política onde à União e aos Estados cabem baixar normas que regulamentam cursos de graduação e pós-graduação. Já aos colegiados das universidades (professores formadores) tem sua própria autonomia de gerenciamento dos cursos, sendo essa autonomia data da seguinte forma:

I- criar, organizar e extinguir, em sua sede, cursos e programas de educação superior previstos nesta Lei, obedecendo às normas gerais da União e, quando for o caso, do respectivo sistema de ensino;

II- fixar os currículos dos seus cursos e programas, observadas as diretrizes gerais pertinentes;

III- estabelecer planos, programas e projetos de pesquisa científica, produção artística e atividades de extensão;

IV- fixar número de vagas de acordo com a capacidade institucional e as exigências do seu meio;

$\mathrm{V}$ - elaborar e reformar os seus estatutos e regimentos em consonância com as normas gerais atinentes;

VI- conferir graus, diplomas e outros títulos;

VII- firmar contratos, acordos e convênios;

VIII- aprovar e executar planos, programas e projetos de investimentos referentes a obras, serviços e aquisições em geral, bem como administrar rendimentos conforme dispositivos institucionais;

IX- administrar os rendimentos e de deles dispor na forma prevista no ato de constituição, nas leis e nos respectivos estatutos;

X- receber
subvenções, doações,
heranças, legados e
cooperação financeira
resultante de convênios
com entidades públicas e
privadas. (DAIVES, 2004,
p.195)

A partir disso, a universidade1 tem autonomia para a organização do currículo, gerenciamento de finanças e projetos de pesquisa, decidindo assim as prioridades e focos de cada curso. Essa autonomia ainda se transpõe de forma que a LDB delibera uma autonomia didático-científica, cabendo ao colegiado decidir sobre ensino, pesquisa e os recursos orçamentários.

Visto isso, o objetivo deste ensaio teórico é discutir a problemática da adequação curricular na formação inicial de professores, a partir de diretrizes estruturadoras dos cursos de licenciaturas, ponderando a importância das ideologias pré-existentes do Professor Formador. Pois, o currículo, seja ele em âmbito da Educação Básica ou do Ensino Superior, apresenta-se em duas formas: o currículo documental, que é o escrito e delimitado por documentos como Projeto Pedagógico e, o real, que é aquele efetivamente executado na prática.

\section{METODOLOGIA}

Este trabalho está pautado na abordagem qualitativa, do tipo exploratória. Na pesquisa qualitativa, "o pesquisador utiliza os insights e as informações provenientes da literatura, enquanto conhecimento sobre o contexto, utilizando-se dele para verificar afirmações e observações a respeito de seu tema de pesquisa" (FLICK, 2009, p.62).

Para compreender melhor os princípios em que se pauta a presente pesquisa, foi realizada uma revisão de literatura sobre a temática de estudo, levando em consideração dois tipos descritores: as legislações e os referenciais teóricos. A teoria, "serve como orientação para restringir a amplitude dos fatos a serem estudados - a quantidade de dados que podem ser estudados em determinada área da realidade, é infinita" (MARCONI; LAKATOS, 2003,

\footnotetext{
${ }^{1}$ Quando tratamos do termo universidade neste caso falamos na composição de sujeitos os professores e gestores
} 
p. 115). Para isso, o trabalho focaliza os principais aspectos explorando suas limitações e principais características do objeto de pesquisa (currículo na formação inicial de professores) possibilitando compreender o que já é conhecido sobre o tema: quais as principais referências, os conceitos e as principais discussões sobre o assunto.

\section{RESULTADOS E DISCUSSÃO}

A construção de um currículo seja ele no Ensino Superior ou na Educação Básica é realizada de forma conjunta entre pessoas de diferentes contextos sociais e formações acadêmicas, a composição de opiniões converge para o que Sácristan (2008, p. 17) descreve como composição do currículo: "a expressão do equilíbrio de interesses e forças que gravitam sistema educativo num dado momento".

Neste caso, traremos para a discussão a importância do pensamento do docente formador pertencentes ao colegiado dos cursos de licenciaturas tanto no ponto de vista pessoal (ideológico), quando no pensamento em grupo (pensamento hegemônico). A consideração de que o professor formador atua de forma não neutra foi considerada por Apple (2008) a partir da deferência de que não se pode separar o profissional do pessoal ao mencionar sua obra anterior "Educação e o Poder (1989)".

Defendi muito fortemente a ideia de que a educação não era um empreendimento neutro e de que, pela própria natureza da instituição, o educador estava envolvido em um ato político, estivesse ciente ou não disso. Sustentei a tese de que, em sua atividade educacional das diferentes reações dos sistemas educacionais e das formas de consciência que dominam economias altamente industrializadas como a nossa (APPLE, 2008, p.35)

Consideramos então que as ideologias e hegemonias dos professores formadores responsáveis pelos cursos inferem nas implantações e adaptações do currículo. Ideologia e Hegemonia no senso comum são sempre levadas como conceitos sociais no

pejorativo. Neste caso, utilizaremos apenas como construções sociais oriundas das vivencias dos docentes formadores, seja na carreira acadêmica ou na vida pessoal, e serão definidas segundo a delimitação de Apple (2008). O conceito de ideologia descrito pelo autor é composto por três categorias que afetariam a prática profissional e a característica desses currículos, estas três categorias são:

(1) racionalizações e justificações bastante específicas das atividades de grupos ocupacionais particulares e identificáveis (ou seja, ideologias profissionais); (2) programas políticos e movimentos sociais mais amplos; (3) Visões de mundo e perspectivas mais abrangentes (APPLE, 2008, p.53).

Já o conceito de hegemonia que utilizaremos neste trabalho foi também descrito pelo autor como:

A hegemonia se refere não
a acumulação de
significados que estão em
um nível abstrato em
algum lugar 'da parte
superior de nossos
cérebros'. Ao contrário,
refere-se a um conjunto
organizado de significados
e práticas, ao sistema
central, eficaz e
dominante de significados,
valores e ações que são
vividos. Precisa ser
entendida em um nível
diferente do que o da
'mera opinião' ou da
'manipulação' (APPLE,
2006, p.39)

Esse tipo de reflexo causado pelos professores formadores nos currículos (Ensino Básico e Superior) não é única e exclusivamente por parte dos professores, mas também do contexto social. Krasilchik (2000) descreve reformas educacionais no ensino de ciências no Brasil de acordo com o momento social do país. Os reflexos do momento social e político no Ensino de Ciências podem ser ilustrados pelo Quadro 1 - Evolução da situação mundial, sendo tendências no Ensino 1950-2000. 
Quadro 1. Evolução da situação mundial, segundo tendências no Ensino 1950-2000.

\begin{tabular}{|c|c|c|c|}
\hline \multirow[b]{2}{*}{$\begin{array}{l}\text { Tendências no } \\
\text { Ensino }\end{array}$} & \multicolumn{3}{|c|}{ Situação mundial } \\
\hline & $\begin{array}{l}1950 \\
\text { Guerra Fria }\end{array}$ & $\begin{array}{l}1970 \\
\text { Guerra Tecnológica }\end{array}$ & $\begin{array}{c}1990 \\
\text { Globalização }\end{array}$ \\
\hline $\begin{array}{l}\text { Objetivo do } \\
\text { Ensino }\end{array}$ & $\begin{array}{ll}\text { - } & \text { Formar Elite } \\
\text { - } & \text { Programas } \\
& \text { Rígidos }\end{array}$ & $\begin{array}{ll}\text { - } & \text { Formar } \\
\text { Cidadão- } \\
\text { trabalhador } \\
\text { - } \quad \text { Propostas } \\
\text { curriculares }\end{array}$ & $\begin{array}{ll}\text { - } & \text { Formar Cidadão- } \\
\text { trabalhador-estudante }\end{array}$ \\
\hline $\begin{array}{l}\text { Concepção de } \\
\text { Ciência }\end{array}$ & $\begin{array}{l}\text { - } \quad \text { Atividade } \\
\text { Neutra }\end{array}$ & $\begin{array}{ll}\text { - } & \text { Evolução da } \\
\text { - } & \text { história } \\
\text { Pensamento } \\
\text { Lógico Crítico }\end{array}$ & $\begin{array}{l}\text { - Atividade com implicações } \\
\text { Sociais }\end{array}$ \\
\hline $\begin{array}{l}\text { Instituições } \\
\text { Promotoras de } \\
\text { reforma }\end{array}$ & $\begin{array}{ll}\text { - } & \text { Projetos } \\
& \text { Curriculares } \\
\text { - } & \text { Associações } \\
& \text { Profissionais }\end{array}$ & $\begin{array}{l}\text { - Centro de } \\
\text { Ciências, } \\
\text { Universidades }\end{array}$ & $\begin{array}{l}\text { - Universidades e Associações } \\
\text { Profissionais }\end{array}$ \\
\hline $\begin{array}{l}\text { Modalidades } \\
\text { didáticas } \\
\text { recomendadas }\end{array}$ & $\begin{array}{l}\text { - } \quad \text { Aulas } \\
\quad \text { Práticas }\end{array}$ & $\begin{array}{l}-\quad \text { Projetos e } \\
\quad \text { Discussões }\end{array}$ & $\begin{array}{l}\text { - Jogos: Exercícios no } \\
\text { computador }\end{array}$ \\
\hline
\end{tabular}

Fonte: KRASILCHIK, 2000, p. 86.

Este reflexo não altera apenas o foco dos currículos da educação básica, mas também a maneira pela qual se forma o professor. Agora que delimitamos como funciona a questão hierárquica das esferas políticas que inferem no currículo e o papel e importância dos docentes formadores, tomaremos uma deliberação do Conselho Estadual de Educação de São Paulo para exemplificação de como a ideologia e a hegemonia dos sujeitos envolvidos importam no currículo.

A Deliberação CEE no 111/2012 (SÃO PAULO, 2012) oriunda do Conselho Estadual de Educação fixa diretrizes Curriculares para a Formação de Docentes para a Educação Básica nos cursos de Graduação de Pedagogia, Normal Superior e Licenciaturas, oferecidos pelos estabelecimentos de Ensino Superior vinculados ao Sistema Estadual de Educação. Esta legislação foi escolhida como fator exemplificador por determinar $30 \%$ da carga horária total2 do currículo seja dedicado à formação didáticopedagógica, além das 400 horas de carga horária das disciplinas de estágio. Além disso, essa legislação adiciona ao currículo das licenciaturas os seguintes aspectos:

\footnotetext{
${ }^{2}$ A carga horária total de 2800 horas para formação de docentes para os anos finais do Ensino Fundamental e Ensino Médio.
}

Quadro 2. Aspectos que foram incluídos nas licenciaturas

Aspectos da Deliberação no 111/2012 que empurram mudanças no currículo de todas as licenciaturas

Estudos de Língua Portuguesa falada e escrita, da leitura, produção e utilização de diferentes gêneros de textos, indispensáveis ao trabalho em sala de aula nos anos finais do ensino fundamental e no ensino médio e ao registro e comunicação de sua experiência docente;

Utilização das Tecnologias de Comunicação e Informação (TICS) como recurso pedagógico e para o desenvolvimento pessoal e profissional;

Fonte: O conteúdo da tabela foi produzido pelos autores a partir da Deliberação no 111/2012 (SÃO PAULO, 2012)

Portanto, essa deliberação tem como objetivo uma formação inicial mais condizente como o momento atual de alta tecnologia e garante também a todos licenciados do estado de São Paulo, o mínimo de $30 \%$ da carga horária dos cursos em disciplinas pedagógicas. Outro ponto que é necessário ser evidenciado desta legislação são às 400 horas de Prática como Componente Curricular ou PCC, esse termo foi descrito pela primeira vez no Parecer CNE/CP no: 28/2001 como: 
A prática como componente curricular é, pois, uma prática que produz algo no âmbito do ensino [...], ela deve ser planejada quando da elaboração do projeto pedagógico e seu acontecer deve se dar desde o início da duração do processo formativo e se estender ao longo de todo o seu processo. Em articulação intrínseca com o estágio supervisionado e com as atividades de trabalho acadêmico, ela concorre conjuntamente para a formação da identidade do professor como educador. A prática, como componente curricular, que terá necessariamente a marca dos projetos pedagógicos das instituições formadoras, ao transcender a sala de aula para o conjunto do ambiente escolar e da própria educação escolar, pode envolver uma articulação com os órgãos normativos e com os órgãos executivos dos sistemas (BRASIL, 2001, p. 11).

Neste caso, a PCC vai de encontro com o ideal de Prática como Componente Curricular de Perrenoud e Thurler (2008), onde não é só "dever" das disciplinas pedagógicas considerar a prática do futuro professor em sala de aula, como apontado pelos autores.

A formação teórica permitia ser aprovado nos exames e obter o diploma, enquanto a formação prática daria as bases para a sobrevivência na profissão. É preciso combater dicotomia e afirmar que a formação é uma só, teórica e prática ao mesmo tempo, assim como reflexiva, crítica e criadora de identidade. Ela acontece em toda parte,

\begin{abstract}
nas aulas e nos seminários, em campo e nos dispositivos de formação que levam os diversos formadores a trabalharem juntos: acompanhamento de atuações profissionais, moderação de grupo de análise de práticas ou reflexão comum sobre problemas profissionais. (PERRENOUD; THURLER, 2008, p.23)
\end{abstract}

Com a troca de currículo que propicie a formação profissional em uma racionalidade prática onde os conhecimentos pedagógicos são tidos apenas como ferramentas para a sala de aula, a quebra deste paradigma no Brasil deixa de ser apenas teórica para a implantação nas universidades. Atrelando a teoria e a prática como na CES no 111/2012 não torna apenas a grade disciplinar algo mais próximo da licenciatura, mas faz com que os alunos desta modalidade entendam a prática docente também como fonte de conhecimento e, a atividade em sala de aula não se resume a mera aplicação de técnicas de forma mecânica.

Esse tipo de mudança postural dentro da licenciatura, ou seja, pensar o licenciando como um futuro professor só se torna possível se a postura dentro do ambiente acadêmico condizer com este tipo de pedagogia. Um caso onde este tipo de mudança dependeria da mudança de pensamento dos professores formadores são os cursos de licenciatura dentro das ciências da natureza (Licenciatura em Física, Química ou Biologia) onde os conteúdos pedagógicos deixariam de ser coadjuvantes e teria um papel principal junto às disciplinas de conteúdo.

Quando a diferença entre a ideologia pedagógica do currículo no papel (delimitado por deliberações, projetos pedagógicos e o próprio currículo) e o real (postura acadêmica dentro da universidade) acaba ocorrendo que, nessa queda de braço algum ponto acaba se sobressaindo e dificilmente os quesitos como PCC e os $30 \%$ de atividades teórico-didáticas seriam cumpridos de forma adequada.

O pensamento dos professores, suas ideologias e formas de entender o mundo e a educação transcendem a discussão para a prática em sala de aula e não fica apenas no âmbito curricular. Esta multiplicidade de características 
na formação docente, comumente é discutida na formação de professores em forma de paradigmas a serem transpassados. Apresentaremos aqui apenas os paradigmas da formação docente contendo as racionalidades técnicas e práticas.

Considerando que partiremos da concepção de que a formação do professor se dá de forma contínua, ou seja, ocorre em um processo onde a formação inicial não é capaz de formar o profissional em sua totalidade e que é necessária uma formação continua atrelada à prática. O modelo da racionalidade técnica, conhecido pela prática profissional dos professores, é norteado pela ênfase na solução das atividades através da aplicação de técnicas de forma instrumental, ou seja, a profissão exercida com uma rigorosa aplicação de teorias cientificas, técnicas e metodologias educacionais. Este tipo de racionalidade teve como grande defensor e influenciou segundo Diniz-Pereira (2014), o psicólogo experimental Skinner3.

Este modelo de racionalidade foi muito criticado, pois o professor era visto como um técnico ou especialista em aplicação de técnicas, sejam elas científicas ou pedagógicas, tornando assim os conhecimentos adquiridos na formação inicial (conhecimentos e habilidades científicos e/ou pedagógicos) meramente aplicáveis no exercício da profissão, tornando a profissão um hábito transmissionista/racionalista.

Já o movimento de prática reflexiva teve como grandes defensores Donald Shön com sua obra The Reflective Practitioner (O profissional reflexivo), 1983, John Dewey "How to think" (Como pensar), 1910. Estas obras inspiraram grandes obras literárias da área, no mundo todo. No Brasil temos como representante Paulo Freire em sua obra "Pedagogia da Autonomia". Apesar de sua obra em si não tratar de uma prática reflexiva como uma formação reflexão-na-ação, dita nestes termos, Paulo Freire descreve e encoraja a formação de um professor educativo progressista. Onde defende que a formação do mesmo não se trata apenas de acúmulo de conhecimento:

Formar é muito mais do que puramente treinar o educando no desempenho de destrezas, e por que não dizer também da quase obstinação com que falo de meu interesse por tudo o que diz respeito aos homens e às mulheres, assunto de que saio e a que volto com o gosto de quem a ele se dá em mim à malvadez neoliberal, ao cinismo de sai ideologia fatalista e sua recusa inflexível ao sonho e á utopia (FREIRE, 2002, p.16)

Mizukami et. al. (2010) quando traduziu em seu livro o artigo "Reflective teacher education; cases and critiques", de Valli (1992), apontou também algumas divisões possíveis dentro da racionalidade prática reflexiva, em seu trabalho ela dividiu esse assunto em quatro níveis: III- Reflexão-na-ação, IV- Deliberação VPersonalista VI- Crítico. Para este trabalho devido à escolha de paradigma escolhemos apenas os Níveis III e IV.

\footnotetext{
${ }^{3}$ Burrhus Frederic Skinner (1904 a 1990), pesquisador da psicologia experimental. Sua obra mais conhecida foi o behaviorismo radical, abordagem que busca entender o comportamento em função das inter-relações entre a filogenética, o ambiente (cultura) e a história de vida.
} 
Quadro 3. níveis de Racionalidade Prática Reflexiva

\begin{tabular}{lll}
\hline Nível de Prática Reflexiva & \multicolumn{1}{c}{ Características } \\
\hline & & O conhecimento da atividade profissional derivado \\
& da prática é valorizado; \\
Reflexão- na -ação & Foco na atividade pedagógica; \\
& - & Fatores contextuais são levados em consideração na \\
& prática pedagógica; \\
\hline Deliberativo & Para a preparação de aulas, considera a reflexão \\
& sobre explicações, perspectivas e teorias \\
& competitivas entre si; \\
& O conhecimento não guia a prática, mas é tida como \\
& informação para a prática.
\end{tabular}

Fonte: Quadro adaptado de Modelos reflexivos de racionalidade (MIZUKAMI et.al. 2010, p. 56) ao traduzir o artigo "Reflective teacher education; cases and critiques" (VALLI 1992, p. 207-218).

A quebra deste paradigma educacional na formação de professores teve sua estruturação na passagem do século XX para 0 $X X I$, estruturado por grandes estudiosos da prática e formação docente. Trabalho como de Donald Shön, Edgar Scheim, Villanas e John Dewey e dos brasileiros Mizukami et.al., que criaram um rico aporte teórico sobre este paradigma. O reflexo da racionalidade técnica na educação brasileira pode ser visto, que muitas escolas e universidades que ainda apresentam em seus currículos e projetos pedagógicos a descrição de metas a serem cumpridas levando em consideração uma racionalidade técnica, da seguinte forma:

Assumindo que o objetivo dos cursos é basicamente transmitir informação, ao professor cabe apresentar a matéria de forma atualizada e organizada, facilitando a aquisição de conhecimentos. Nos anos 60 , o processo ensinoaprendizagem era influenciado pelas ideias de educadores comportamentalistas que recomendavam a apresentação de objetivos do ensino na forma de comportamentos

observáveis, indicando formas de atingi-los e indicadores mínimos de desempenho aceitável (KRASILCHIK, 2000, p. 87).

No Brasil, os esforços para que ocorra a quebra da formação na racionalidade técnica e a troca para a formação de uma racionalidade prática que possibilite a reflexão na ação, vem surgindo em legislações estaduais no estado de São Paulo, desde 2012 e, nacionais, desde o ano de 2015.

O parecer CES no 111/2012 (SÃO PAULO, 2012), que foi responsável pelas alterações curriculares realizadas para a turma de ingressantes de 2015, apresenta um caráter de valorização do professor reflexivo e da articulação entre a teoria e prática pedagógica, garantindo ao currículo o mínimo de $30 \%$ das disciplinas de caráter pedagógico e as PCCs.

Apesar da formação deste currículo propiciar um curso com "cara de licenciatura", com a troca de currículo que propicie a formação profissional em uma racionalidade prática, a quebra deste paradigma no Brasil, deixa de ser apenas teórica para a implantação nas universidades. Atrelando a teoria e a prática como na CES no 111/2012 não torna apenas a grade disciplinar algo mais próximo da licenciatura, mas faz com que os alunos da licenciatura entendam a prática docente também como fonte de conhecimento e, a atividade em sala de aula não se resume a mera aplicação de técnicas de forma mecânica.

\section{CONCLUSÕES}

Como vimos aqui a construção do currículo seja ele legislativo ou o real depende das ideologias e hegemonias dos sujeitos que realizam a sua composição. Como resultados deste trabalho sugere-se que apenas as normas não deveriam ser apenas impostas de forma verticalizada União/Estado-Universidade, necessita-se também intervenções junto aos colegiados, onde o professor formador tenha acesso não apenas as mudanças no currículo, mas 
também as suas importâncias e possibilidades de alteração curricular.

Neste caso, torna-se importante esse tipo de formação continuada para o professor formador, devido o fato de que muitos dos professores atuantes nas licenciaturas não têm como formação inicial a licenciatura ou como pós-graduação cursos na área de Educação, fica difícil à interpretação de termos técnicos como a Prática como Componente Curricular. Também consideramos que como posição assumida neste trabalho que a formação do professor é realizada de forma contínua, seja ele professor de Ensino Básico ou Superior, não tendo sua contemplação total ao final da graduação.

Este tipo de formação também se torna necessária para que haja um espaço de reflexão dos formadores quanto ao que é formar um professor e a cultura em que sua vivência dentro da universidade. Possibilitando assim uma ruptura ideológica do formador e, também, construindo e desequilibrando hegemonias já existentes no âmbito dos colegiados da universidade.

\section{REFERÊNCIAS}

APPLE, M W. Educação e Poder. Porto Alegre:

Artes Médicas Editora, 2008, 201 p.

APPLE, M. W. Ideologia e Currículo. 3. ed. Porto Alegre: Artmed Editora, 2006, 288 p.

BRASIL. Conselho Nacional de Educação. Parecer CNE/CP no 28/2001. Duração e carga horária dos cursos de Formação de Professores da Educação Básica, em nível superior, curso de licenciatura, de graduação plena. Aprovado em 02/10/2001. Publicado em 18/01/2002. Disponível em: < http://portal.mec.gov.br/cne/arquivos/pdf/028.p df.> Acesso em:

\section{DAIVES, N. Legislação Educacional Federal}

Básica. 2. ed. São Paulo: Editora Cortez, 2004, $215 \mathrm{p}$.

DINIZ-PEREIRA, J. E. Da Racionalidade técnica à racionalidade crítica: formação docente e transformação social, Perspectivas em Diálogo: Revista de Educação e Sociedade, v.01, n.01, p. 34-42, jan-jun.2014.

FLICK, U. Introdução à pesquisa qualitativa. 3 . ed. Porto Alegre: Artmed Editora, 2009. 405 p.
FREIRE, P. Pedagogia da Autonomia. 42. ed. São Paulo. Paz e Guerra, 2002.

KRASILCHIK, M. Reformas e realidade: o caso do ensino de Ciências. São Paulo em Perspectiva, v. 14, n. 1, p. 85-93, 2000. Disponível em: < http://www.scielo.br/scielo.php?script=sci_arttex t\&pid=S0102-

$88392000000100010 \& \operatorname{lng}=p t \& t \operatorname{lng}=p t .>\quad$ Acesso em: 7 julho de 2017. DOI: 10.1590/S010288392000000100010

\section{MARCONI, M. A; LAKATOS, E. M. Fundamentos} de metodologia científica. 5. ed. São Paulo: Atlas, 2003, $311 \mathrm{p}$.

MIZUKAMI, M. da G. N. et. al. Escola e aprendizagem da docência: processos de investigação e formação. 2. ed. Editora: RiMa Artes e Texto, 2010, $201 \mathrm{p}$.

PERRENOUD, P.; THURLER, M. G. As competências para ensinar no século XXI: a formação dos professores e o desafio da avaliação. Tradução Cláudia Schilling e Fátima Murad. 2. ed. Porto Alegre: Artmed Editora, $2008,288 p$.

SACRISTÁN, J. C. O currículo: uma reflexão sobre a prática. 3. ed. Porto Alegre: Artmed Editora, 2008, 352 p.

SÃO PAULO (Estado). Secretaria estadual de Educação. Conselho Estadual de Educação. Deliberação CEE no111/2012: Fixa Diretrizes Complementares para a formação de Docentes par a Educação Básica nos Cursos de Graduação de pedagogia, Normal Superior e Licenciaturas, oferecidos pelos estabelecimentos de Ensino Superior vinculados ao sistema estadual. Aprovado em 01 de fev. de 2012. Publicado no DOE em 03 de fev. de 2012. Disponível em: < http://www.fct.unesp.br/Home/Graduacao/Peda gogia/deliberacoes-cee-111-de-2012-e-126-de2014.pdf.> Acesso em: 07 de julho de 2017.

VALLI, L. Ed. Reflective teacher education; cases and critiques. New Your, State University of New Yourk Press. 1992. 281 p.

Recebido para publicação em: 27/10/2017

Revisado em: 18/11/2017

Aceito em: 28/01/2018 